\title{
Development of martensitic transformation induced by severe plastic deformation and subsequent heat treatment in polycrystalline $\mathrm{Ni}_{52} \mathrm{Mn}_{24} \mathrm{Ga}_{24}$ alloy
}

\author{
I.I. Musabirov ${ }^{1 \dagger}$, I.M. Safarov ${ }^{1}$, R.R. Mulyukov ${ }^{1}$, I.Z. Sharipov ${ }^{1,2}$, V.V. Koledov ${ }^{3}$ \\ †irekmusabirov@imsp.ru
}

${ }^{1}$ Institute for Metals Superplasticity Problems, RAS, 39 Khalturin St., 450001, Ufa, Russia

${ }^{2}$ Ufa State Aviation Technical University, 12 K. Marx, 450000, Ufa, Russia

${ }^{3}$ Institute of Radioengineering and Electronics, RAS, 11-7 Mokhovaya, 125009, Moscow, Russia

\begin{abstract}
The results of a study of the martensitic transformation in the polycrystalline $\mathrm{Ni}_{52} \mathrm{Mn}_{24} \mathrm{Ga}_{24}$ alloy in different structural states are presented in the article. In the initial state in the alloy magnetic and martensitic phase transformation is observed with the following characteristic points: $M_{\mathrm{S}}=25^{\circ} \mathrm{C} ; M_{\mathrm{F}}=15^{\circ} \mathrm{C} ; A_{\mathrm{S}}=35^{\circ} \mathrm{C} ; A_{\mathrm{F}}=45^{\circ} \mathrm{C} ; T_{\mathrm{C}}=127^{\circ} \mathrm{C}$. The alloy in the initial state, after intensive plastic deformation by high pressure torsion and after the stepped annealing of the deformed material at temperatures of $400^{\circ} \mathrm{C}, 500^{\circ} \mathrm{C}$ and $600^{\circ} \mathrm{C}$ was investigated. The microstructure of the alloy was investigated by means of scanning electron microscope equipped by the detector sensitive to orientation contrast of material. Analysis of the microstructure of the alloy in the initial state shows that the average grain size is $270 \mu \mathrm{m}$. In the alloy after plastic deformation and subsequent annealing at $400^{\circ} \mathrm{C}$, this value is $180 \mathrm{~nm}$. Annealing at $500^{\circ} \mathrm{C}$ and $600^{\circ} \mathrm{C}$ leads to an increase in the average grain size up to $1.08 \mu \mathrm{m}$ and $2.33 \mu \mathrm{m}$, respectively. The results of the study of the microhardness of the alloy in different structural states are presented. As a result of plastic deformation of the alloy the microhardness increases from $2.1 \mathrm{GPa}$ in the initial state to 5.1 GPa in the deformed state. After annealing, a gradual decreasing of the microhardness down to $2.8 \mathrm{GPa}$ is found. The temperature dependence of magnetization of the alloy in different structural states shows that as a result of severe plastic deformation the ferromagnetic order is destroyed and the martensitic transformation is suppressed. After stepped annealing at $400^{\circ} \mathrm{C}, 500^{\circ} \mathrm{C}$ and $600^{\circ} \mathrm{C}$, there is a gradual recovery of ferromagnetic order. The martensitic transformation is observed in the alloy only after annealing at $500^{\circ} \mathrm{C}$. In this case the average grain size is increased to $1 \mu \mathrm{m}$.
\end{abstract}

Keywords: shape memory alloys, ferromagnetic shape memory alloys, martensitic transformation, plastic deformation, NiMnGa alloy.

\section{Introduction}

Heusler Ni-Mn-Ga alloys belong to the class of promising functional materials. In these materials in the range of room temperatures the martensitic transformation is observed, which progresses in the ferromagnetic state of the alloy. Due to these properties, ferromagnetic materials have a shape memory effect [1-4], a magnetocaloric effect [5-10], etc.

A shape memory effect, controlled by an external magnetic field, opens prospects to use this material as a functional element in various kinds of actuators, microelectronics [1114] etc. The disadvantage of these alloys in the initial state is the low thermostability of the functional properties. As a result of the repeated cycles of martensitic transformation the sample is destroyed [15]. The solution of this problem is a formation of the fine-grained structure in the material. The sample having such a structure does not fail after the repeated cycles [16]. For getting such a structure different methods of deformation and heat treatment [17-21] are used. The sample has a limited size when using high pressure torsion (HPT). However, this method allows studying the evolution of the martensitic transformation in the alloy in different structural states. This paper presents the results of a study of the martensite transformation in a polycrystalline $\mathrm{Ni}_{52} \mathrm{Mn}_{24} \mathrm{Ga}_{24}$ alloy subjected to HPT and the stepwise annealing.

\section{Methodology}

As the material for the research the polycrystalline $\mathrm{Ni}_{52} \mathrm{Mn}_{24} \mathrm{Ga}_{24}$ alloy was selected. Alloy was produced by arc melting in an Ar atmosphere of $\mathrm{Ni}, \mathrm{Mn}$ and $\mathrm{Ga}$ of high purity. For homogenization, the samples were annealed for 9 days at $827^{\circ} \mathrm{C}$, followed by quenching in ice water. The ingot of alloy has an elongated shape (rod shape), because the melt crystallization was held in an elongated copper crucible with recess and the size $10 \mathrm{~mm} \times 100 \mathrm{~mm}$.

The microstructure of the material in the initial state was investigated by optical methods. In the initial state, optical microscopy technique allows one to distinguish such structural elements as grains and martensitic plates. After deformation and annealing at different temperatures, grain structure of the alloy, was investigated by scanning 
electronmicroscopy (SEM) equipped by the detector sensitive to orientation contrast of material. This method is the most convenient for studying of fine-grained structure because it does not require any labour-intensive preparation of thin foils and allows analyzing a large surface area of the material. After polishing on the abrasive paper, the surface of the sample was exposed to electrolytic polishing.

Microhardness measurements were carried out according to GOST $9450-76$ by Vickers method on the optical microscope Axiovert 100A. The microscope is equipped with an attachment for measuring microhardness MNT-10. The load for indentation was chosen to be $F=2 N(200 \mathrm{~g})$ from the condition $d=0.7 \mathrm{H} \mu \mathrm{m}$, where $\mathrm{d}$ is the indent diagonal length, $\mathrm{H}$ is the thickness of the sample. Microhardness was measured from the center to the edge of the sample, making 10 indents on the site. The measurement error was less than $10 \%$.

The martensitic transformation study was performed using the recording of the temperature dependence of the magnetization in the magnetic field of about $240 \mathrm{kA} / \mathrm{m}$. The recording was carried out by heating the sample in the range of the existence of the martensitic and magnetic phase transitions. Measurement of the magnetization of the sample was carried out on automatic magnetic microbalance, which was described in the following paper [22].

\section{Results and discussion}

The analysis of the martensitic transformation in a polycrystalline $\mathrm{Ni}_{52} \mathrm{Mn}_{24} \mathrm{Ga}_{24}$ alloy in different structural states begins with the study of the microstructure of the material in each of the studied states.

Figure 1a is an optical image of the microstructure of the alloy in the initial state. It is seen that the structure has a large number of microcracks extending along the grain boundaries. As the structure investigation is carried out at room temperature, the microbands (martensite plates) in grains are observed. At this temperature the austenitic and martensite phases coexist.

The microcracks nucleation appears in the alloy due to the anisotropic change of the grain's shape and size as the result of the crystal lattice transformation during the martensitic transformation. Since the grains have different crystallographic orientation, the shape change in different directions causes a microstrain and a dislocation nucleation near the grain boundaries. Formation of the dislocation clusters on the boundaries initiates the nucleation of microcracks, which are exposed on further thermal cycling and cause the destruction of the material.

The study of the microstructure of the alloy after HPT by using SEM is greatly complicated because the structure is amorphous and cold-worked. Consequently, the structure of the deformed material was investigated only after annealing at $400^{\circ} \mathrm{C}, 500^{\circ} \mathrm{C}$ and $600^{\circ} \mathrm{C}$.

Figure $1 \mathrm{~b}$ shows the microstructure of the alloy after $\mathrm{HPT}$ and subsequent annealing at $400^{\circ} \mathrm{C}$. It is seen that due to the heat treatment, the partial recrystallization of structure arises. Grains are not homogeneous in size, therefore the recrystallization process is not uniform. The statistical
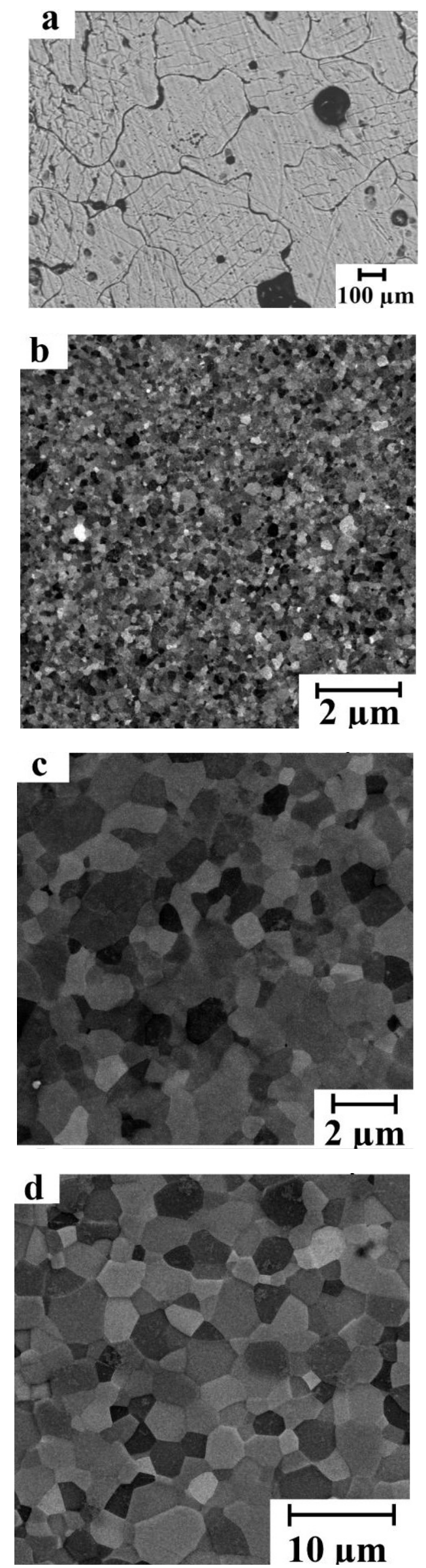

Fig. 1. Structure of $\mathrm{Ni}_{52} \mathrm{Mn}_{24} \mathrm{Ga}_{24}$ alloy. (a) Optical image of the structure in the initial state; (b)-(d) SEM image after HPT and annealing at $400^{\circ} \mathrm{C}, 500^{\circ} \mathrm{C}$ and $600^{\circ} \mathrm{C}$, respectively. 


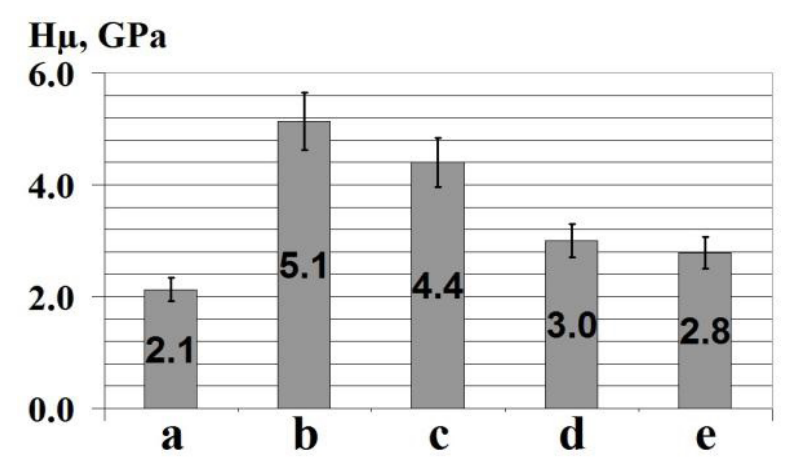

Fig. 2. Microhardness of alloy in the various states: (a) initial state; (b) after HPT; (c) HPT and annealing at $400^{\circ} \mathrm{C}$; (d) HPT and annealing at $500^{\circ} \mathrm{C}$; (e) $\mathrm{HPT}$ and annealing at $600^{\circ} \mathrm{C}$.

analysis shows that the average grain size in this case is 180 $\mathrm{nm}$. After annealing at $500^{\circ} \mathrm{C}$ and $600^{\circ} \mathrm{C}$, the development of recrystallization processes leads to an increase of the average grain size to $1.08 \mu \mathrm{m}$ and $2.33 \mu \mathrm{m}$, respectively (Fig.1c,d).

The analysis of the recrystallization process after severe plastic deformation (SPD) is conveniently carried out according to the dependence of the microhardness of the material on annealing temperature. Figure 2 is a diagram showing the dependence of the microhardness from the alloy states obtained by the various heat treatments.

As it follows from the diagram, in the initial state the microhardness is about 2.1 GPa. As a result of HPT, this value increases abruptly more than twofold, reaching $5.1 \mathrm{GPa}$. Subsequent annealing at $400^{\circ} \mathrm{C}, 500^{\circ} \mathrm{C}$ and $600^{\circ} \mathrm{C}$ leads to a gradual reduction in the value of microhardness.

Consider how the martensitic transformation is implemented in the alloy in different structural states. A study of this phase transformation was carried out by the recording of the temperature dependence of the alloy magnetization by heating the sample in the temperature range of martensitic and magnetic phase transformations. The magnetic field applied to the sample is about $240 \mathrm{kA} / \mathrm{m}$. The relevant data are presented in Fig.3.

As it is seen from the figure, in the initial state the two phase transformations are observed. When the sample is

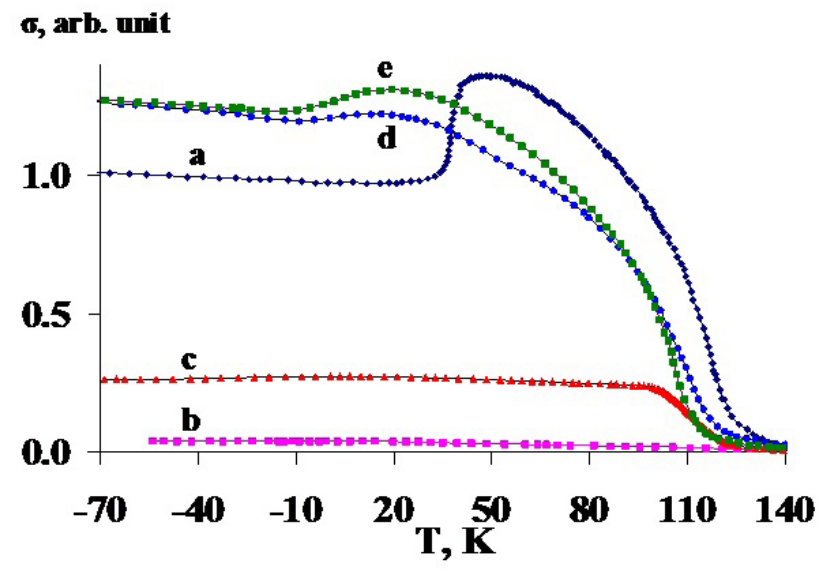

Fig. 3. The temperature dependence of magnetization of alloy in the various states. (a) initial state; (b) after HPT; (c) HPT and annealing at $400^{\circ} \mathrm{C}$; (d) $\mathrm{HPT}$ and annealing at $500^{\circ} \mathrm{C}$; (e) $\mathrm{HPT}$ and annealing at $600^{\circ} \mathrm{C}$. heated in the temperature range from $35^{\circ} \mathrm{C}$ to $45^{\circ} \mathrm{C}$ the reverse martensitic transformation is occurred (Fig.3a). The result of the phase transformation is an abrupt change in the magnetization of the sample. With the further increase of temperature, the magnetization falls and at the temperature of $125^{\circ} \mathrm{C}$ the sample transforms from ferromagnetic to the paramagnetic state. This behavior of the materials magnetization is characteristic for the alloys of this system. Martensite phase has a large value of the magnetocrystalline anisotropy constant. During the martensitic transformation the twin structure is formed. The twins themselves are broken down into $180^{\circ}$ magnetic domains. As a result, the magnetization of the sample falls.

It is also known that the ferromagnetic order is damaged as a result of the SPD of the alloys [16]. The temperature magnetization dependence of the investigated alloy shows that the magnetic order in the sample is practically not observed (Fig.3b). The major role plays the size factor. In nanocrystalline grains the martensitic transformation is suppressed, and the magnetic domains are absent.

The annealing of the alloy at $400^{\circ} \mathrm{C}$ after SPD leads to the partial recovery of the ferromagnetic order. As it is seen from Figure $3 \mathrm{c}$ the magnetization of the sample on the horizontal area is below this value before the annealing. In the region of martensitic transformation existence the linear variation of the magnetization is observed. It indicates that the martensitic transformation is not restored yet.

With the increase of the annealing temperature, the magnetization in the ferromagnetic state is increased. On the curve $\sigma(T)$ for the sample annealed at $500^{\circ} \mathrm{C}$ in the region of martensitic phase existence the small bend is observed. It indicates that in this state, the martensitic transformation is partially implemented. As it is mentioned above, in such a recrystallized structure the average grain size is $1.08 \mathrm{mkm}$. The detailed analysis of the microstructure of the alloy in this state shows that at room temperature in some grains the martensitic structure is found.

The annealing of the alloy at $600^{\circ} \mathrm{C}$ leads to a further increase of the sample magnetization in the ferromagnetic state. In this case the bend on $\sigma(T)$ in the region of martensitic phase existence is manifested more clearly.

\section{Conclusions}

Thus, the analysis of the martensitic transformation in a polycrystalline alloy after HPT and subsequent stepwise annealing at $400^{\circ} \mathrm{C}, 500^{\circ} \mathrm{C}$ and $600^{\circ} \mathrm{C}$, leads to the following conclusions.

In a polycrystalline $\mathrm{Ni}_{52} \mathrm{Mn}_{24} \mathrm{Ga}_{24}$ alloy the martensitic and magnetic phase transitions with the following characteristic points: $M_{S}=25^{\circ} \mathrm{C} ; M_{F}=15^{\circ} \mathrm{C} ; A_{S}=35^{\circ} \mathrm{C} ; A_{F}=45^{\circ} \mathrm{C} ; T_{C}=127^{\circ} \mathrm{C}$ are found.

The SPD leads to the fragmentation of the grain structure and the damage of the ferromagnetic order. The stepwise annealing of deformed samples leads to recrystallization of the grain structure. After annealing at $600^{\circ} \mathrm{C}$, the average grain size is $2.33 \mu \mathrm{m}$. Annealing leads to the gradual recovery of the ferromagnetic order.

Martensitic transformation in the material after the 
SPD is also absent. The partial martensitic transformation is observed after annealing at $500^{\circ} \mathrm{C}$. The average grain size in this case is about $1 \mu \mathrm{m}$.

This work was supported by grant of the Russian Foundation for Basic Research 14-02-31699 mol_a.

\section{References}

1. W.H. Wang, F.X. Hu, J.L. Chen, Y.X. Li, Z. Wang, Z.Y. Gao, Y.F. Zheng, L.C. Zhao, G.H. Wu, W.S. Zan. IEEE Transact. Magn. 37(4), 2715 (2001).

2. Kh. Ya. Mulyukov, I. I. Musabirov. The Russian J. of App. Phys. 53(6), 802 (2008).

3. I.I. Musabirov, K.Y. Mulyukov, V.V. Koledov, V.G. Shavrov. The Russian J. of App. Phys. 56(3), 423 (2011).

4. Kh. Ya. Mulyukov, I.I. Musabirov, R.R. Mulyukov, V.V. Koledov, V.G. Shavrov, V.G. Pushin. The Phys. of Met. and Metallogr. 112(5), 488 (2011).

5. Y. Liu, X. Zhang, D. Xing, H. Shen, D. Chen, J. Liu, J.Sun. J. of All. and Comp. 616, 184 (2014).

6. K. Y. Mulyukov, I. I. Musabirov, A. V. Mashirov. Letters on Materials. 2(4), 194 (2012).

7. S. Pramanick, S. Giri, S. Majumdar, S. Chatterjee, V.V. Koledov, A. Mashirov, A.M. Aliev, A.B. Batdalov, B. Hernando, W. O. Rosa, L. González-Legarreta. J. of All. and Comp. 578, 157 (2013).

8. V.D. Buchelnikov, M.O. Drobosyuk, E.A. Smyshlyaev, O. O. Pavlukhina, A.V. Andreevskikh, S. V. Taskaev, A. A. Fediy, V. V. Koledov, V.G. Shavrov, V. V. Khovaylo, V.V. Sokolovskiy. Solid State Phenomena. 168-169, 165 (2011).

9. A. M. Aliev, A.B. Batdalov, I. K. Kamilov, V. V. Koledov,
V.G. Shavrov, V.D. Buchelnikov, J. García, V.M. Prida, B. Hernando. Appl. Phys. Lett. 97(21), 212505 (2010).

10. V.A. Chernenko, J.M. Barandiaran, J.R. Fernandez, D. P. Rojas, J. Gutierrez, P. Lazpita. I. Orue. JMMM. 324 (21), 3519 (2012).

11. E.T. Kalimullina, A.P. Kamantsev, V.V. Koledov. Nelineinyi Mir. 12(2), 42 (2014). (in Russian)

12. A.V. Irzhak, D.I. Zakharov, V.S. Kalashnikov, V.V. Koledov, D.S. Kuchin, G.A. Lebedev, P.V. Lega, E.P. Perov, N.A. Pikhtin, V.G. Pushin, I.S. Tarasov, V.V. Khovailo, V. G. Shavrov, A. V. Shelyakov. J. of Comm. Tech. and Electr. 55(7), 818 (2010).

13. Patent RUS 2305874, 10.09.2007.

14. R.M. Gizatullin, V.V. Koledov, V.G. Pushin, A. N. Chekhovoy. Composite Materials Constructions. 3, 57 (2007).

15. F. Xiong, Y. Liu, E. Pagounis. JMMM. 285(3), 410 (2005).

16. R.N. Imashev, Kh.Ya. Mulyukov, I.Z. Sharipov, V.G. Shavrov, V.V. Koledov. Phys. of Solid State. 47(3), 556 (2005).

17. A. A. Samigullina, R. K. Khisamov, R.R. Mulyukov. Letters on Materials. 2(3), 134 (2012).

18. R. N. Imashev, V. V. Koledov, I.Z. Sharipov, V. G. Shavrov, Kh. Ya. Mulyukov. Phys. of Solid State. 47(10), 1944 (2005).

19. R. R. Mulyukov. Nanotechnologies in Russia. 2(7-8), 38 (2007).

20. R. R. Mulyukov, A.A. Nazarov, R.M. Imayev. Russian Physics J. 51(5), 492 (2008).

21. I.M. Safarov, A.V. Korznikov, S.N. Sergeev, S. V. Gladkovskii, E. M. Borodin. The Phys. of Met. and Metallogr. 113(10), 1001 (2012).

22. Kh. Ya. Mulyukov, I.Z. Sharipov, S.S. Absalyamov. Instruments and Experimental Techniques. 41(3), 433 (1998) . 